\title{
Pineal Gland Transplants into the Cerebral Hemisphere of Newborn Rats: A Study of the Blood Brain Barrier and Innervation
}

\author{
J.A. McNulty, L.M. Fox, P.L. Shaw, V.E. Alones, B.S. Klausen, \\ R.S. Swenson, and A.J. Castro \\ Department of Anatomy, Stritch School of Medicine \\ Loyola University, Maywood IL 60153, USA
}

\begin{abstract}
Reprint address:
Dr. John A. McNulty

Department of Anatomy

Loyola University Medical Center

2160 S. First Avenue

Maywood, IL 60153

USA
\end{abstract}

SUMMARY

Pineal glands from neonatal (0-1 day) Long-Evans black-hooded rats were transplanted into the cerebral hemispheres of litter mates for periods of 1 to 5.5 months. Grafts exhibited differentiated pinealocytes that were intensely immunoreactive for serotonin. Transplant vasculature was permeable to endogenous IgG, comprised fenestrated endothelia with wide pericapillary spaces typical of in situ glands, and had a volume density intermediate to that of surrounding cortex and in situ pineals. Along the periphery, transplant capillaries tended to have continuous endothelia similar to those of host cortex. This peripheral zone was impermeable to endogenous IgG and appeared to increase in size in older grafts. The presence of noradrenergic-like fibers within the perivascular compartment suggested that transplants were innervated by peripheral sympathetic neurons from the superior cervical ganglia. In animals which had been superior cervical ganglionectomized, noradrenergic-like fibers were absent or degenerating. Neural regulation of transplant metabolic activity was suggested by the increased frequency of pinealocyte synaptic ribbons in denervated grafts. These findings are consistent with the hypothesis that factors from both graft and host influence vasculature physiology and differentiation in neural transplants. Furthermore, grafts appeared to receive appropriate neural input from the peripheral sympathetic system.

\section{KEY WORDS}

Serotonin; synaptic ribbon; sympathetic; superior cervical ganglionectomy; ultrastructure 


\section{INTRODUCTION}

The pineal gland, a neuroendocrine gland of diencephalic origin, exhibits several characteristics that make it a useful model for transplantation studies concerning mechanisms of the blood brain barrier (BBB) and innervation. First, the pineal gland of rats is normally vascularized by fenestrated, permeable blood vessels with wide pericapillary spaces /11,22/. Second, it receives a well defined sympathetic innervation from the superior cervical ganglion (SCG) which is necessary for the normal circadian production of the pineal hormone, melatonin $/ 26 /$. The sympathetic innervation is identified ultrastructurally by the presence of characteristic dense-core vesicles within the sympathetic terminals $/ 21 /$. Third, the pineal gland contains high concentrations of the indoleamine, serotonin (5HT), and is the principal source of circulating melatonin. These indoles, which exhibit robust circadian rhythms and are easily measured by both biochemical and histochemical methods, provide important markers of the functional integrity of the transplant. Finally, pinealocytes have ultrastructure features such as the synaptic ribbon that provide unequivocal identification of donor vs host tissues $/ 23 /$.

The present study examined various anatomical features of the newborn pineal gland grafted into cerebral neocortical lesion cavities made in newborn rats. Particular emphasis was placed on the ultrastructural differentiation of transplant pinealocytes and the vascularization of the graft. Recent studies of neuronal transplant vasculature have demonstrated an impermeable BBB within fetal neocortical grafts placed intracerebrally in newborn rats $/ 32 /$. Using adult recipients, similar findings have been reported for hypothalamic grafts $/ 3,36 /$, although other evidence indicates a permeable blood supply for neocortical grafts located intraventricularly $/ 16,30 /$. In comparison to central nervous system (CNS) transplants, grafts of peripheral autonomic tissue (i.e., superior cervical ganglia and adrenal medulla) demonstrated a permeable BBB $/ 29,31 /$.

In the present report, intracerebral grafts of the neonatal pineal gland into newborn hosts demonstrated a permeable vasculature to circulating macromolecules. These findings corresponded to ultrastructural observations of fenestrated endothelial cells comparable to the normal in situ gland. The innervation of grafts by apparent sympathetic fibers prompted further studies to determine whether this noradrenergic input influenced grafted pinealocyte function.

\section{MATERIALS AND METHODS}

Long-Evans, black-hooded rats were used. The pineal gland of 0-1 day-old rats was dissected under hypothermic anesthesia into sterile Ringer's solution and gently aspirated into a glass pipet glued to the tip of a $50 \mu \mathrm{m}$ Hamilton syringe. Simultaneously, small neocortical lesions were made by aspiration into litter mates also anesthetized by hypothermia. The recipient lesions were made $1-2 \mathrm{~mm}$ from the midline just rostral to the coronal suture and grafts were immediately placed into the lesion cavity by slowly ejecting them from the syringe canula with the aid of a micromanipulator. The grafts were held in place by a flap of the cartilaginous skull and the pups were warmed by an incandescent lamp before returning them to their mothers. Donor rats were killed by decapitation while under hypothermic anesthesia. The results reported in this study are from 28 rats receiving such transplants.

After 1 to 5.5 months, animals were overdosed with sodium pentobarbital and perfused with physiological saline followed by a $4 \%$ paraformaldehyde $/ 0.1 \%$ glutaraldehyde solution. In eight rats the SCG were surgically removed (SCGX) bilaterally under sodium pentobarbital anesthesia $(45 \mathrm{mg} / \mathrm{kg}) 5-7$ days prior to sacrifice.

Tissue blocks containing the transplant were vibratome sectioned at $50-100 \mu \mathrm{m}$ and examined either with Nissl or immunohistochemically for serotonin and IgG as previously described /32/. Transplant blood vessel permeability to endogenous immunoglobulin ( $\mathrm{IgG}$ ) was analyzed by incubating tissue in biotinylated rabbit anti-rat IgG (1:200). Serotonin positive pinealocytes were demonstrated using rabbit anti-serotonin antiserum (INCstar, Stillwater, MN at 1:100-1:1500) followed by incubation with biotinylated goat anti-rabbit IgG (1:200). AvidinBiotin histochemistry was performed according to the protocol in the Vectastain $A B C$ kit (Vector Labs, Burlington, CA) using the chromogen diaminobenzidine. Immunoreacted sections were also 
processed for routine electron microscopy. Sections were post-fixed in osmium tetroxide, dehydrated in ethanol followed by propylene oxide and flat embedded on plastic slides with epoxy resin. After the blocks were cured, the transplants were photographed for purposes of orientation and the transplants cut out and remounted on plastic stubs for sectioning. Toluidine blue $1 \mu \mathrm{m}$ sections from these blocks were photographed for purposes of orientation in the electron microscope and were used to estimate volume density of blood vessels $\left(\mathrm{Vv}_{\mathrm{bv}}\right)$ with a 90 -point grid on a transparent overlay and applying standard stereological point-counting methodologies $/ 35 /$. Thin sections $(70-80 \mathrm{~nm})$ were examined with an Hitachi $\mathrm{H}$ 600 TEM operated at $75 \mathrm{kV}$. Counts of pinealocyte synaptic ribbons were obtained by systematically scanning three grid spaces (300 mesh; Pelco, Tustin, CA) at a magnification of $\times 6,000$ on the microscope screen. Each of the grids was coded so that the individual performing the counts was unfamiliar with the experimental group. Differences between the means were statistically analyzed by the Student's ttest (2-tailed).

\section{RESULTS}

Transplants were located within the cortical lesion cavity near the cortical surface (Fig. 1), bordering the lateral ventricle (Fig. 2) or within the lateral ventricle (Fig. 3). Pineal tissue was easily distinguished from surrounding cortex with Nissl stain (Figs. 1c, 2a) and revealed positive immunoreactivity for both IgG (Figs. 1a,b,2b) and serotonin (Fig. 3). The IgG immunoreactivity sometimes had a trabecular appearance corresponding to the vasculature of the gland (Fig. 1a). In some transplants, especially older ones, the IgG immunoreactivity was greatest in the central part of the transplant and declined in intensity toward the periphery of the graft (Fig. 1b,2b). Morphometric analysis of the transplant vasculature revealed that capillary volume density: (1) did not differ between transplants located in the cortex and ventricle; and (2) had a mean value which was intermediate to that of in situ pineal glands and the surrounding cortex (Table 1). Capillary volume densities of individual transplants fell within the ranges of values calculated for cortex and in situ glands (Table 1).
TABLE 1

MEANS ( \pm SEM) OF VOLUME DENSITIES $\left(\mathrm{mm}^{3} / \mathrm{mm}^{3}\right)$ OF VASCULARIZATION IN TRANSPLANTS COMPARED TO CORTEX AND IN SITU GLANDS

\begin{tabular}{lccc}
\hline & Mean & SEM & Range \\
\hline $\begin{array}{l}\text { In situ glands } \\
(\mathrm{n}=6)\end{array}$ & .236 & \pm .038 & $.214-.414$ \\
$\begin{array}{c}\text { Transplants } \\
(\mathrm{n}=15)\end{array}$ & .127 & \pm .018 & $.032-.242$ \\
$\begin{array}{c}\text { Cortical } \\
(\mathrm{n}=11)\end{array}$ & .123 & \pm .022 & $.032-.228$ \\
$\begin{array}{c}\text { Ventricular } \\
(\mathrm{n}=4)\end{array}$ & .139 & \pm .037 & $.070-.242$ \\
\begin{tabular}{c} 
Cortex $(\mathrm{n}=9)$ \\
\hline
\end{tabular} & .037 & \pm .006 & $.017-.057$ \\
\hline
\end{tabular}

The fine structure of transplant pinealocytes was indistinguishable from that of in situ cells (Fig. 4a). Cytoplasmic organelles were well differentiated and included the synaptic ribbon which is characteristic of this cell type (Fig. 4b). The ultrastructure of the vasculature was variable. Within the central part of the transplant, capillary endothelia were attenuated and had fenestrae with diaphragms (Fig. 5). The HRP immunoreaction product for IgG was located in the wide perivascular space (Figs. 5b,d). Fenestrated endothelia were observed within all transplants although the frequency of fenestrae was reduced in those transplants located within the ventricle. Along the periphery of transplants, capillaries tended to resemble host cortical tissue lacking both fenestrae and a wide perivascular compartment (Fig. 6). Nerve terminals containing clear and dense-cored vesicles 40 $60 \mathrm{~nm}$ in diameter were observed in the perivascular spaces (Figs. 5A,7). The nerve fibers tended to be more common in grafts located within the cortex as compared to those lying within the lateral ventricle.

Superior cervical ganglionectomy resulted in the complete degeneration of noradrenergic-like perivascular terminals in six out of eight in situ glands analyzed. Counts of synaptic ribbons in these six animals were significantly elevated above unoperated controls (Table 2). Although all eight animals which had undergone SCGX experienced bilateral ptosis, in two of these animals noradrenergic terminals were infrequently observed within the gland, suggesting that denervation was not complete. The counts of synaptic 

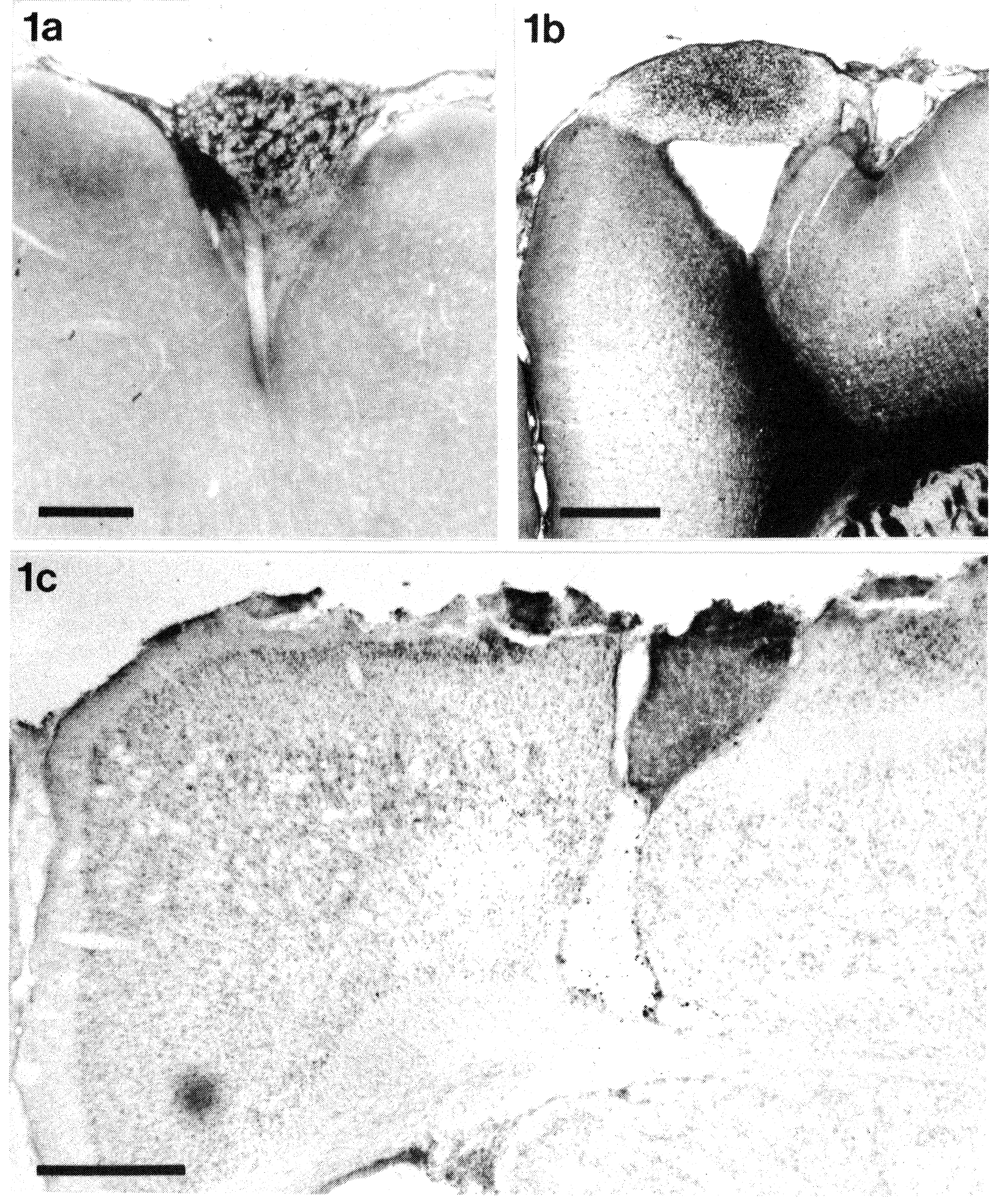

Fig. 1: Examples of grafts in the cortex.

A. 1-month-old graft immunoreacted for IgG. Bar indicates $200 \mu \mathrm{m}$. B. 5-month-old graft immuno-reacted for lgG. Bar indicates $500 \mu \mathrm{m}$. C. 5-month-old graft with Nissl stain. Bar indicates $500 \mu \mathrm{m}$. 
ribbons in these two animals did not differ from unoperated controls and were therefore not included in the statistical analysis presented in Table 2.
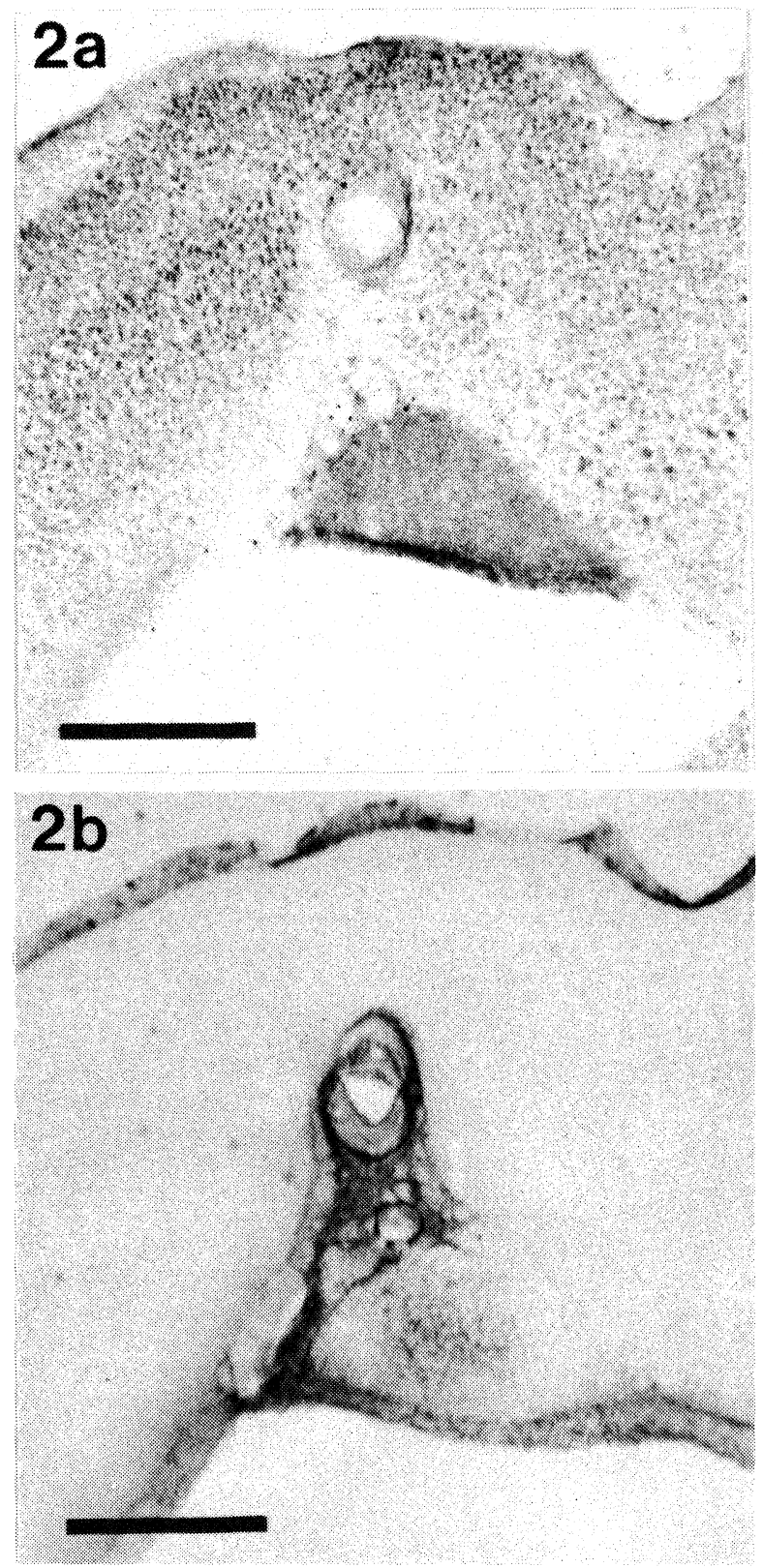

Fig. 2: Adjacent sections from a graft bordering the lateral ventricle. 6-month-old graft. Bars indicate $500 \mu \mathrm{m}$. A. Nissl stain. B. IgG immunoreacted section with reaction product confined to the center of the graft.
TABLE 2

MEAN ( \pm SEM) COUNTS OF SR $\left(\# / 20,000 \mathrm{~mm}^{2}\right)$ AFTER DENERVATION

\begin{tabular}{lccc}
\hline & Mean & SEM & Range \\
\hline $\begin{array}{l}\text { In situ } \\
\text { with NE terminals } \\
(\mathrm{n}=6)\end{array}$ & 37.4 & \pm 3.6 & $25.2-52.6$ \\
$\begin{array}{l}\text { without NE terminals } \\
(\mathrm{n}=6)\end{array}$ & 143.8 & $\pm 20.5^{*}$ & $84.7-201.5$ \\
$\begin{array}{l}\text { Transplants } \\
\text { with NE terminals } \\
(\mathrm{n}=3)\end{array}$ & 44.2 & \pm 15.0 & $22.9-73.2$ \\
$\begin{array}{l}\text { without NE terminals } \\
(\mathrm{n}=7)\end{array}$ & 119.3 & $\pm 10.0^{*}$ & $68.7-144.0$ \\
\hline
\end{tabular}

*Indicates significant differences at $\mathrm{p}<0.05$.

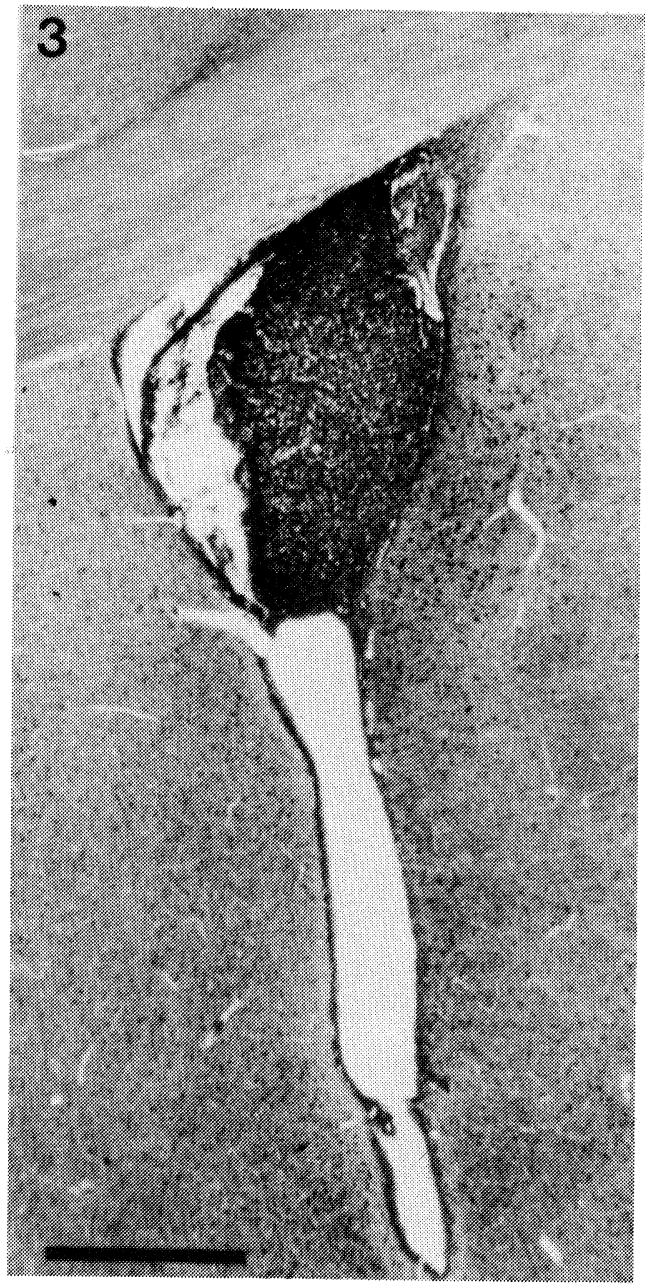

Fig. 3: Transplant reacted with anti-5HT within the lateral ventricle. 2-month-old graft. Bar indicates $500 \mu \mathrm{m}$. 

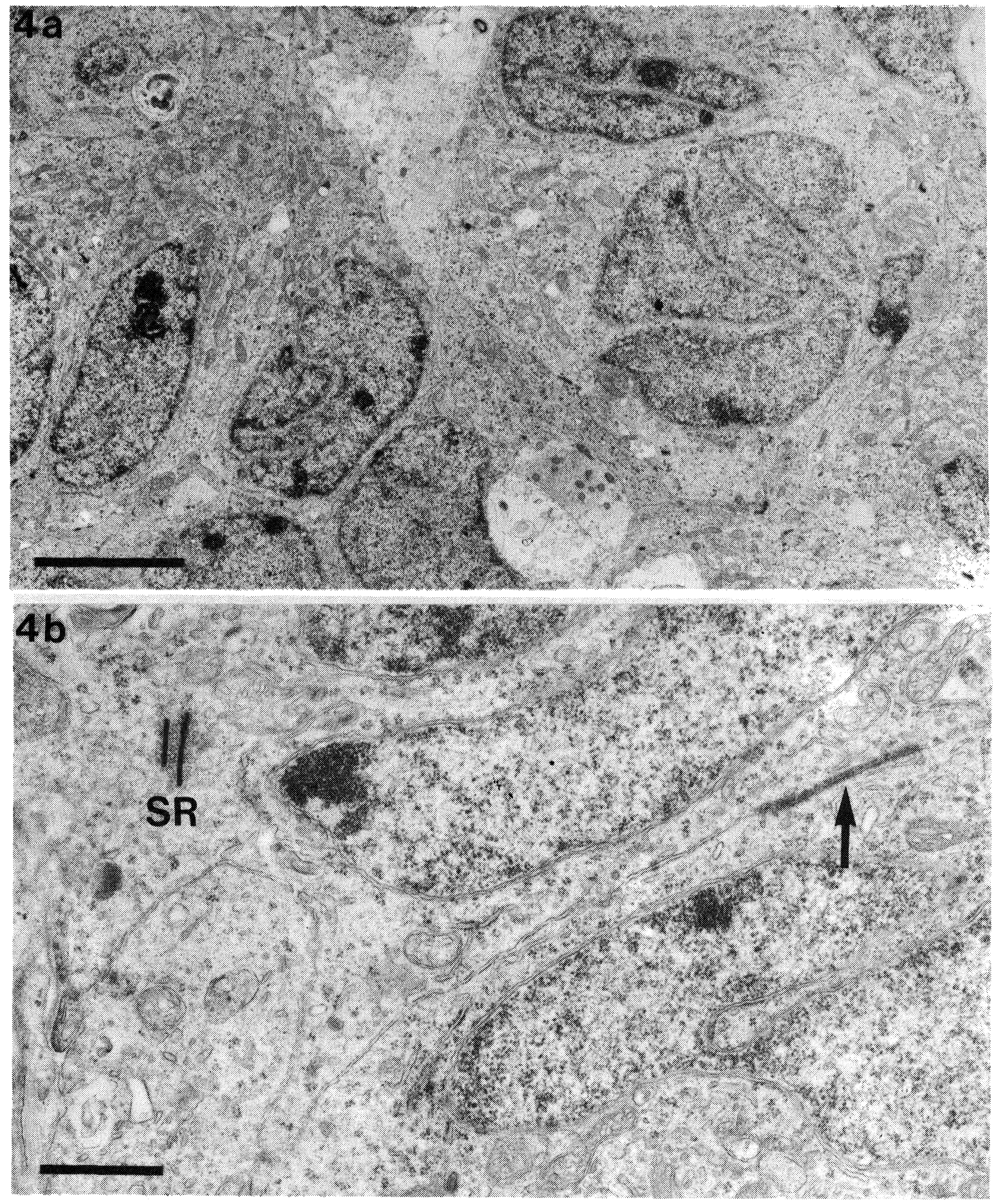

Fig. 4: A. Survey electron micrograph of pinealocytes in a 4-month-old transplant. Pinealocytes are highly differentiated and contain all of the usual organelles. Bar indicates $5 \mu \mathrm{m}$. B. Higher magnification of pinealocytes from the transplant depicted in Fig. 4A illustrating the characteristic synaptic ribbons (SR) and an extensive junctional complex between adjacent cells (arrow). Bar indicates $1 \mu \mathrm{m}$. 
PINEAL GLAND TRANSPLANTS
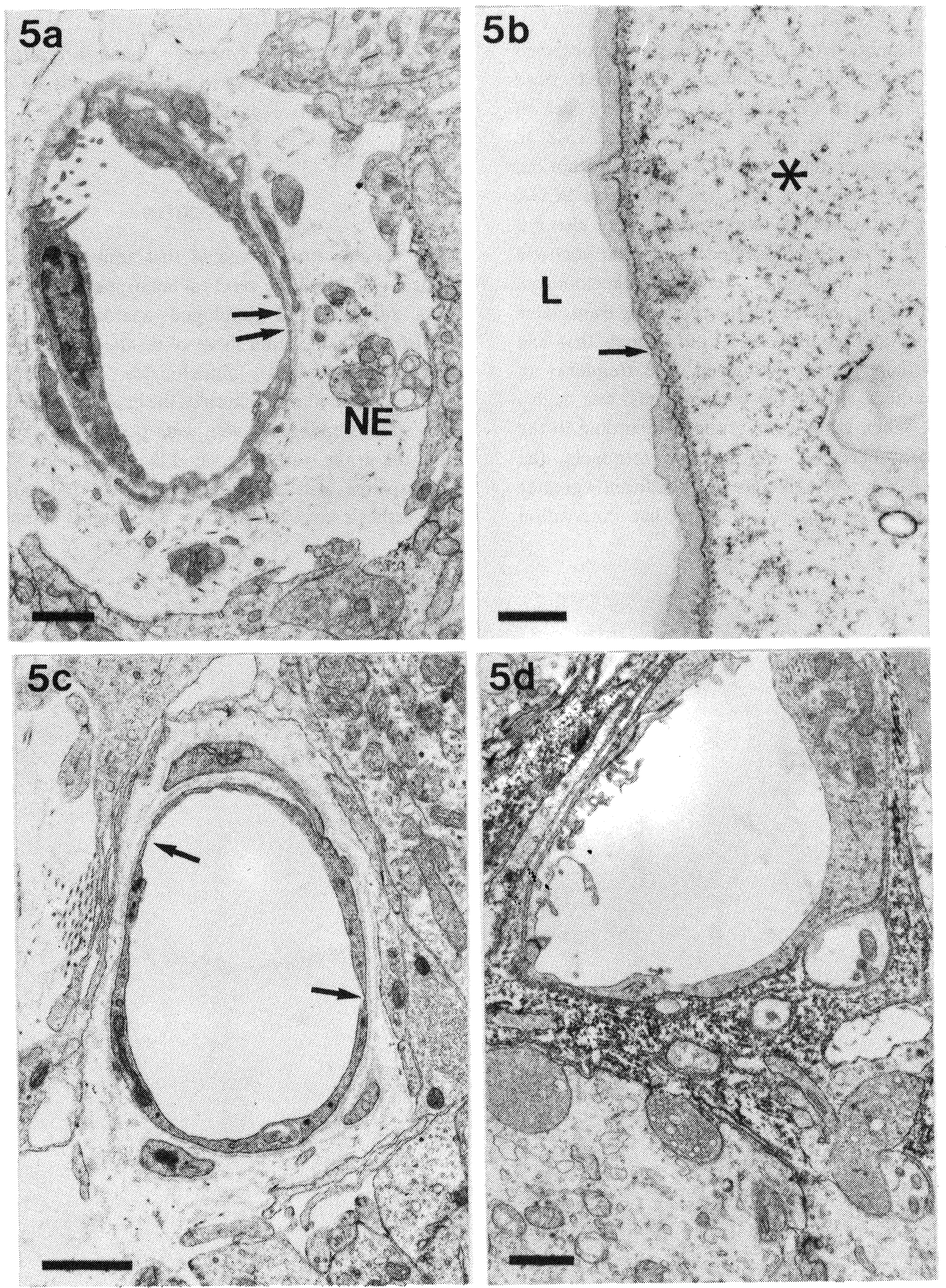

Fig. 5: A. Capillary in 1-month-old graft located in the cortex illustrating the fenestrae (arrows) in the endothelia and noradrenergic nerve fibers (NE) in the perivascular space. Bar indicates $1 \mu \mathrm{m}$. B. Cortically-located pineal graft with fenestrated endothelial cell (arrow) and (IG immunoreaction product in the wide perivascular compartment (asterisk). $L=$ capillary lumen. Bar indicates $0.5 \mu \mathrm{m}$. C. Capillary from 2-month-old transplant in lateral ventricle. The endothelium is fenestrated (arrows) and there is a wide pericapillary space. Bar indicates $1 \mu \mathrm{m}$. D. Capillary with IgG reaction product in the pericapillary space. 5-month-old transplant in the lateral ventricle. Bar indicates $1 \mu \mathrm{m}$. 
Noradrenergic-like terminals were never observed within transplants of animals that had been sympathectomized (as judged by ptosis and lack of terminals within the in situ gland). In one case an apparent degenerating terminal was found within the transplant of an animal that had undergone SCGX (Fig. 7c). Noradrenergic-like terminals were also not detectable in one graft located within the ventricle from an animal that had not been sympathectomized. Terminals were observed in the remaining transplants from innervated controls and from animals that had been partially sympathectomized. The frequency of nerve endings within these transplants was highly variable. When grafts were grouped according to the presence/absence of noradrenergic terminals, the frequency of synaptic ribbons was significantly greater in transplants lacking noradrenergic-like innervation
(Table 2). Counts of synaptic ribbons in grafts with sympathetic terminals were not significantly different from in situ control glands.

\section{DISCUSSION}

The present study revealed that transplants of the pineal gland into the cerebral hemisphere of newborn rats survived and developed anatomical features indistinguishable from those of in situ glands. By one month transplant pinealocytes were highly differentiated ultrastructurally, the capillaries exhibited fenestrated endothelia with wide pericapillary spaces, and the grafts were innervated by sympathetic fibers. Transplants also appeared capable of indoleamine biosynthesis as evidenced by the intense immuno-
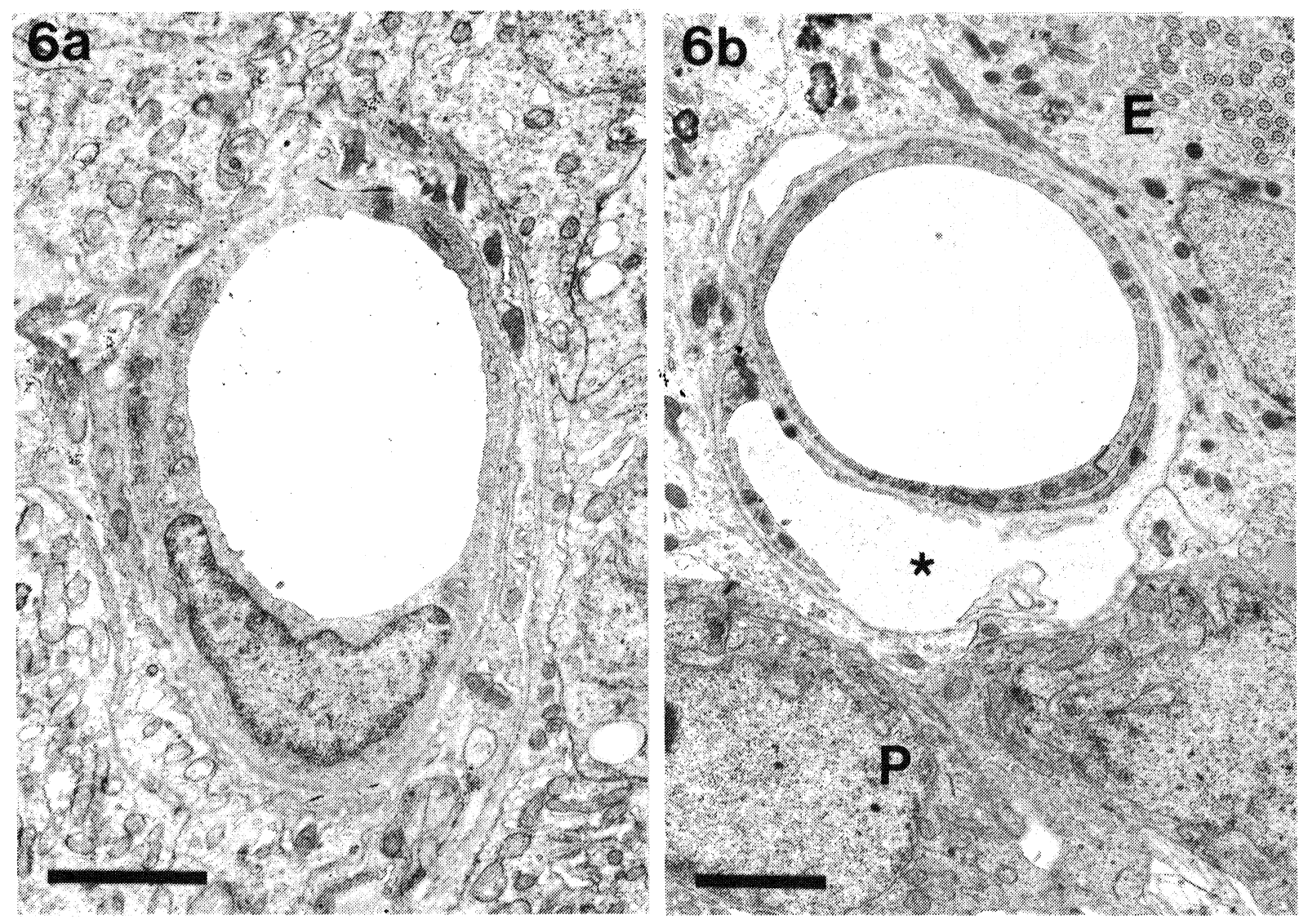

Fig. 6: A. Capillary located along the periphery of 1-month-old graft located in the cortex. The endothelium is continuous with a narrow pericapillary space. Pinealocytes completely surround this capillary. Bar indicates $2 \mu \mathrm{m}$. B. Non-fenestrated capillary along the border of a graft in the lateral ventricle. Note that the pericapillary space is wider (asterisk) where it borders pinealocytes (P) compared to where it borders ependyma $(E)$. Bar indicates $2 \mu \mathrm{m}$. 

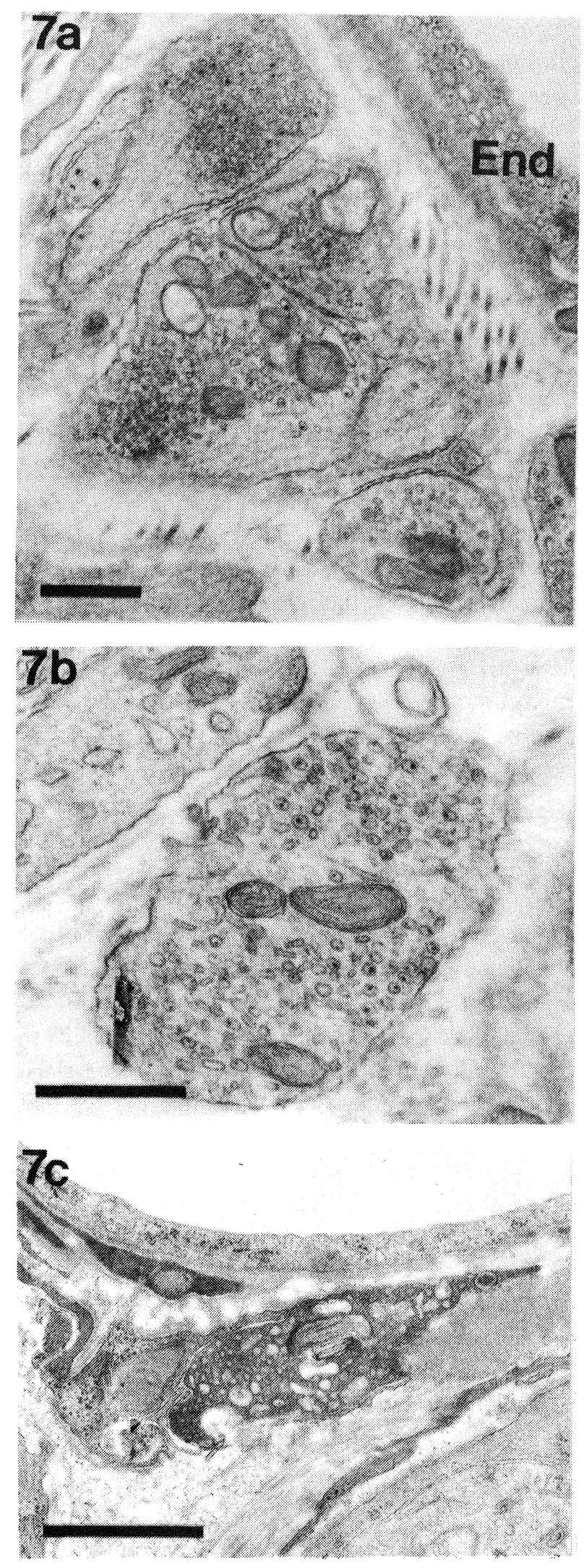

reactivity to serotonin antisera. Survival and differentiation of pineal tissue from adult rats and hamsters into the fourth and lateral ventricles of adult hosts has been previously reported $/ 2,10,18 /$.

Previous work involving the transplantation of fetal neocortex into the cerebral hemisphere of newborn rats demonstrated a transplant vasculature that was impermeable to exogenous or endogenous macromolecules $/ 32 /$. In the present report, similarly placed newborn pineal grafts demonstrated a permeable BBB. These contrasting findings suggest that transplant vascular differentiation and physiology is determined by the graft and not the host tissue. Because the neonatal grafts and hosts used in these studies were undergoing endothelial differentiation and proliferation at the time of transplant, it is conceivable that graft vascularization comprised both native and host vessels. Concerning pineal grafts, the high volume density of capillaries, which in some grafts was identical to that of in situ glands, further suggests the proliferation of native transplant vessels. In this regard it is noteworthy that pineal tissue contains substantial amounts of "endothelial cell stimulating angiogenesis factor (ESAF)" /33/. The possibility that host vessels also supply the graft is supported by the occurrence of capillaries with continuous endothelia along the periphery of transplants. These peripherally located vessels showed a morphology typical of CNS capillaries suggesting that host vessels penetrated the graft to anastomose with existing capillaries /15,17/. An ingrowth of renal vessels into neocortical tissue grafted in the subcapsular space of the kidney further supports the possibility that host vessels are able to penetrate transplants of neural tissue /28/. Furthermore, nonneuronal host cells have been shown to invade fetal tectal tissue grafted to the midbrain of newborn rats $/ 20 /$.

Fig. 7: Examples of noradrenergic nerve terminals in pineal glands. A. Nerve terminals in the perivascular space of a 1-month-old transplant lying in the cortex. End=endothelium. Bar indicates $5 \mu \mathrm{m}$. B. Higher magnification of noradrenergic-like terminal in 1-month-old transplant illustrating the clear and dense-cored vesicles. Bar indicates $5 \mu \mathrm{m}$. C. Degenerating nerve terminal in the perivascular space from a 4month-old transplant that had undergone SCGX. Bar indicates $1 \mu \mathrm{m}$. 
IgG immunoreactivity within the parenchyma of the grafts as well as in the host circumventricular organs and the median eminence /32/ correspond to the presence of a permeable BBB that is morphologically characterized by fenestrated endothelial cells. The absence of IgG immunoreactivity along the margins of some of our grafts indicates an impermeability that corresponded to the observed non-fenestrated endothelium in these regions. Appearing larger in some of our older surviving animals, the peripheral impermeable zone may reflect an age-related increasing invasion of host vessels into the transplants. This possibility could be tested by examining transplants beyond the 5.5 month survival period used in the present experiment.

Instead of representing an ingrowth of host vessels, the impermeable graft margins may alternatively represent a zone where diffusible factors from the host brain and/or transplant influence vessel permeability characteristics. Varying concentrations of such factors may account for the observed differences in size of this zone in different animals. Altered capillary permeability occurs in the dystrophic Royal College of Surgeons (RCS) rats when the retinal photoreceptors degenerate concomitant with neovascularization of the retinal pigment epithelium (RPE) /5,8,9/. These new vessels originate from inner retinal vessels $/ 5 /$ and are modified both morphologically and functionally. When surrounded by the RPE, the new vessels are fenestrated and the plasma membrane composition is altered $/ 5,8 /$. This suggests that the RPE has transformed these retinal vessels from a continuous, nonpermeable endothelium to a fenestrated, permeable one $/ 4,5 /$.

Transplants exhibited a pattern of innervation by noradrenergic-like neurons within the perivascular spaces which is typical of that observed in situ. These observations prompted experiments to determine whether the noradrenergic fibers were of CNS origin (locus coeruleus) or of peripheral origin (SCG). Normally, there is a widespread ascending noradrenergic innervation of the brain from the locus coeruleus $/ 12,27$ / in addition to peripheral sympathetic fibers from the SCG which follow the vasculature of the CNS. After specific brain lesions (medial septum, globus pallidus), a proliferation and invasion of peripheral noradrenergic fibers from the SCG was observed $/ 6,7 /$. Consequently, our placement of grafts into neocortical lesion cavities may have induced an ingrowth of peripheral fibers as a result of the lesion. In support of this possibility, noradrenergic terminals were either absent or in degenerative stages in the transplants of animals that sustained complete SCGX. This evidence for SCG innervation, which is also supported by the observed increase in pinealocyte synaptic ribbons after SCGX, is qualified by one animal that was not surgically sympathectomized and yet whose pineal transplant also lacked evidence of noradrenergic innervation. Accordingly, the absence of terminals in the surgical group is not proof that they were removed by peripheral sympathectomy.

The pineal gland normally exhibits a 24-hour rhythm in melatonin production that is dependent on its SCG innervation $/ 26 /$. If, as our denervation experiments suggest, the transplants are innervated by sympathetic fibers from the SCG, it would be important to determine whether this connectivity establishes the rhythmic production of melatonin over the 24-hour light:dark cycle. Cyclical production of melatonin has been described in pineals transplanted into the anterior chamber of the eye after reinnervation by sympathetic fibers which normally innervate the iris $/ 1,19,25 /$.

Our data on the frequency of pinealocyte synaptic ribbons suggest that the sympathetic innervation to transplants is functional. The significantly greater number of ribbons found in transplants without noradrenergic terminals paralleled the rise observed in denervated in situ glands. Pinealocyte synaptic ribbons normally exhibit quantitative changes related to alterations in the melatonin production by the gland /cf 23/. Several studies have further suggested that these organelles play a role in B-adrenergic mechanisms controlling the rate of melatonin biosynthesis /13,14,24,34/. Because synaptic ribbon frequency in transplants appears dependent upon sympathetic innervation, this organelle could be an important marker to further test the hypothesis that sympathetic innervation of the grafts conveys appropriate information capable of synchronizing graft metabolic activities to the light:dark cycle.

\section{ACKNOWLEDGEMENTS}

This study was supported by the NIH (NS13230 to AJC) and the NSF (BNS 8801726 to JAM). We are 
grateful for the comments and suggestions of Drs. MEC Fitzgerald and EB Pedersen.

\section{REFERENCES}

1. Backstrom M, Olson L, Seiger A. N-acetyltransferase and hydroxyindole-O-methyltransferase activity in intraocular pineal transplants: diurnal rhythm as evidence for a functional sympathetic adrenergic innervation. Acta Physiol Scand 1976; 96:64-71.

2. Brightman MW, Markey SP, Kein DC. Cotransplants of pineal gland and superior cervical ganglion to the IVth ventricle. In A Bjorklund and U Stenevi (Eds.), Neural grafting in the mammalian CNS. New York: Elsevier, 1985, pp. 235-241.

3. Broadwell RD, Charlton HM, Ganong WF, Salcman M, Sofroniew M. Allografts of CNS tissue possess a bloodbrain barrier 1. Grafts of medial preoptic area in hypogonadal mice. Exp Neurol 1989; 105:135-151.

4. Burns MS, Bellhorn RP, Korte GE, Herior WJ. Plasticity of the retinal vasculature. In N Osborne, G Chader (Eds.), Progress in retinal research. New York: Pergamen Press, 1986, pp. 253-307.

5. Caldwell RB, Slapnick SM, Roque RS. REP-associated extracellular matrix changes accompany retinal vascular proliferation and retinal-vitreal membranes in a new model for proliferative retinopathy. In MM LeVail, GE Anderson, JG Hollyfield (Eds.), Inherited and environmentally induced retinal degenerations. New York: Alan R Liss, 1989 , pp. 393-407.

6. Crutcher KA. Cholinergic denervation of rat neocortex results in sympathetic innervation. Exp Neurol 1981; 74:324-329.

7. Crutcher KA, Marfut CF. Nonregenerative axonal growth within the mature mammalian brain: ultrastructural identification of sympathohippocampal sprouts. J Neurosci 1988; 8:2289-2302.

8. Fitzgerald MEC, Slapnick SM, Caldwell RB. Alterations in lectin binding accompany increased permeability in the dystrophic rat model for proliferative retinopathy. In MM LaVail, GE Anderson, JG Hollyfield (Eds.), Inherited and environmentally induced retinal degenerations. New York: Alan R Liss, 1989, pp. 408416.

9. Frank RN, Das A. Models of retinal neovascularization in the rat. Invest Ophthalmol Vis Sci (Suppl) 1989; 29:245.

10. Gibbs FP, Petterborg LJ, Rudeen PK, Scott DR. Reproductive effects of pineal gland transplants in the third cerebral ventricle of blinded olfactory bulbectomized rats. Anat Rec 1989; 223:42A.

11. Hewing M, Bergmann M. Differential permeability of pineal capillaries to lanthanum ion in the rat (Rattus norvegicus), gerbil (Meriones unguiculatus) and golden hamster (Mesocricetus auratus). Cell Tiss Res 1985; 241:149-154.
12. Jones BE, Moore RY. Ascending projections of the locus coeruleus in the rat. II. Autoradiographic studies. Brain Res 1977; 127:23-53.

13. King TS, Dougherty WJ. Age-related changes in pineal "synaptic" ribbon populations in rats exposed to continuous light or darkness. Amer J Anat 1982; 163:169-179.

14. King TS, Doughtery WJ. Effect of denervation on "synaptic" ribbon populations in the rat pineal gland. J Neurocytol 1982; 11:19-28.

15. Krum JM, Rosenstein JM. Patterns of angiogenesis in neural transplant models: I. Autonomic tissue transplants. J Comp Neurol 1987; 258:420-434.

16. Krum JM, Rosenstein JM. The fine structure of vascular-astroglial relations in transplanted fetal neocortex. Exp Neurol 1989; 103:203-212.

17. Krum JM, Rosenstein JM. Patterns of angiogenesis in transplant models: II. Fetal neocortical transplants. J Comp Neurol 1988; 271:331-345.

18. Li K, Welsh MG. Ultrastructure of superficial pineal gland grafts in the third ventricle. Anat $\operatorname{Rec} 1989$; 223:126A.

19. Lingappa JR, Zigmond RE. Pineal transplants in oculo: limitations on the ability of collateral sprouts of foreign neurons to establish normal function. J Neurosci 1987; 7:3525-3528.

20. Lund RD, Harvey AR. Transplantation of tectal tissue in rats. 1. Organization of transplants and pattern of distribution of host afferents within them. J Comp Neurol 1981; 201:191-209.

21. Matsushima S, Reiter RJ. Fine structural features of adrenergic nerve fibers and endings in the pineal gland of the rat, ground squirrel and chinchilla. Amer J Anat 1977; 148:463-478.

22. McNulty JA. Blood circulation of the pineal gland. In DI Abramson and PB Dobrin (Eds.), Blood vessels and lymphatics in organ systems. New York: Academic Press, 1984, pp. 308-311.

23. McNulty JA. Phylogeny and functional implications of synaptic ribbons in the pineal gland. IRCS Med Sci 1986; 14:855-858.

24. McNulty JA, Prechel MM, van de Kar LD, Fox LM. Effects of isoproterenol on synaptic ribbons in pinealocytes of the rat and C57BL/6J mouse. J Pineal Res 1989; 7:305-311.

25. Moore RY. Pineal transplants to the anterior chamber of the eye: Evidence for function reinnervation. Exp Neurol 1975; 49:617-621.

26. Moore RY. The innervation of the mammalian pineal gland. Progr Reprod Biol 1978; 4:1-29.

27. Morrison JH, Grzanna R, Molliver ME, Coyle JT. The patterns of noradrenergic innervation in rat neocortex: An immunohistochemical study. J Comp Neurol 1978; 181:17-40.

28. Naradzay JFX, Rosenstein JM. Vascular morphology and permeability in fetal CNS grafts to the renal capsule. Exp Neurol 1989; 104:284-291. 
29. Rosenstein JM. Adrenal medulla grafts produce bloodbrain barrier dysfunction. Brain Res 1987; 414:192-196.

30. Rosenstein JM. Neocortical transplants in the mammalian brain lack a blood-brain barrier to macromolecules. Science 1987; 235:772-774.

31. Rosenstein JM, Brightman MW. Alterations of the blood-brain barrier after transplantation of autonomic ganglia into the mammalian central nervous system. J Comp Neurol 1986; 250:339-351.

32. Swenson RS, Shaw P, Alones V, Kozlowski G, Zimmer J, Castro AJ. Neocortical transplants grafted into the newborn rat brain demonstrate a blood-brain barrier to macromolecules. Neurosci Lett 1989; 100:35-39.

33. Taylor CM, McLaughlin B, Weiss JB, Smith I. Bovine and human pineal glands contain substantial quantities of endothelial cell stimulating angiogenic factor. J Neural Trans 1988; 71:79-84.

34. Vollrath $\mathrm{L}$, Howe $\mathrm{C}$. Light and drug induced changes of epiphysial synaptic ribbons. Cell Tissue Res 1976; 165:383-390.

35. Weibel ER, Bolender RP. Stereological techniques for electron microscopy. In MA Hayat (Ed.), Principles and techniques of electron microscopy: Biological applications. New York: Van Nostrand Reinhold, 1973, pp. 237-296.

36. Wiegand SJ, Gash DM. Characteristics of vasculature and neurovascular relations in intraventricular anterior hypothalamic transplants. Brain Res Bull 1988; 20:105124. 

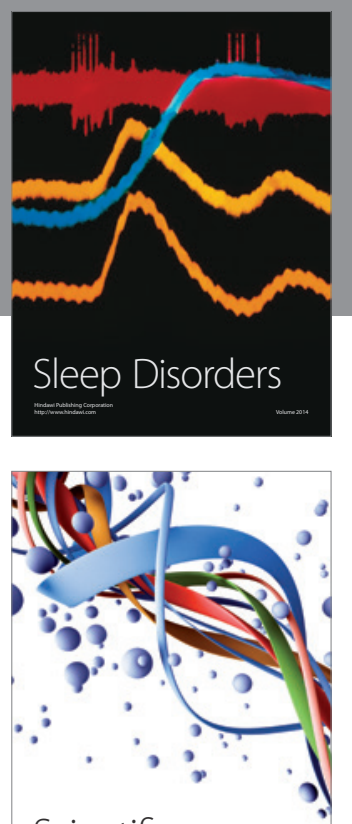

Scientifica
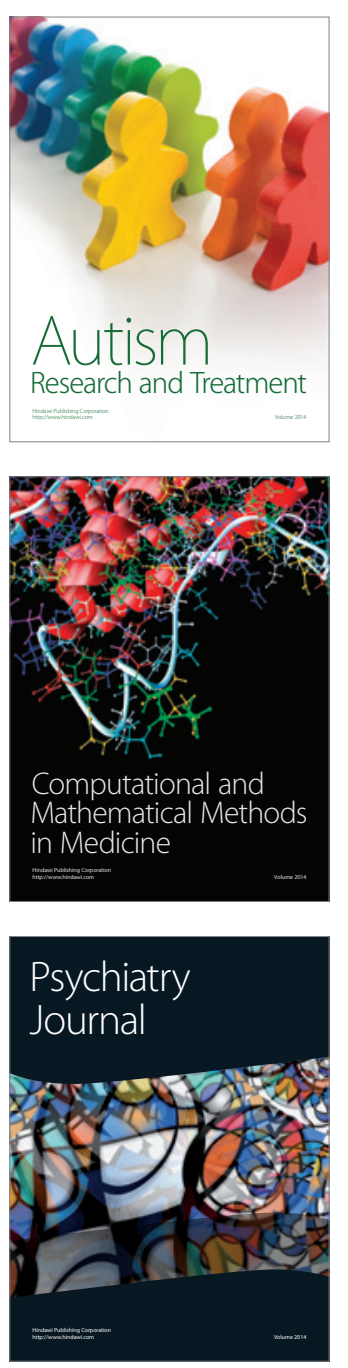
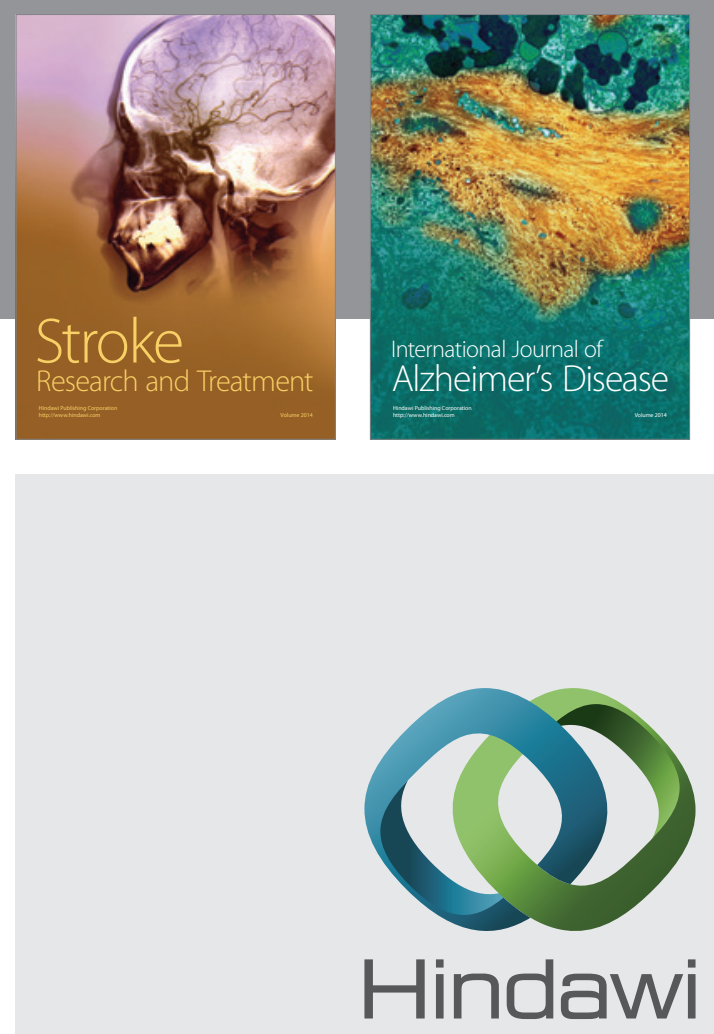

Submit your manuscripts at

http://www.hindawi.com
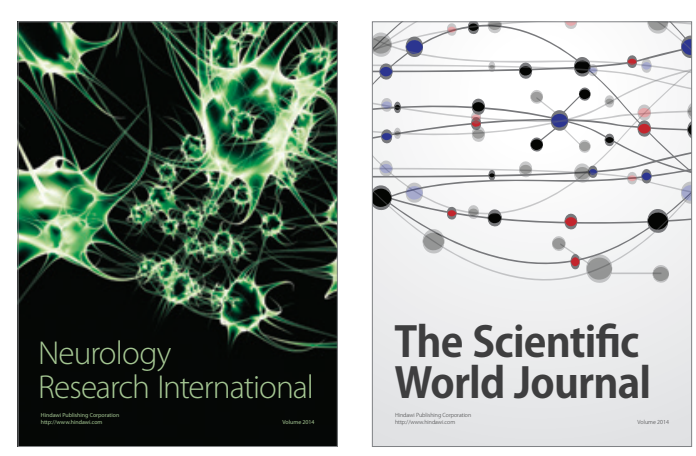

The Scientific World Journal

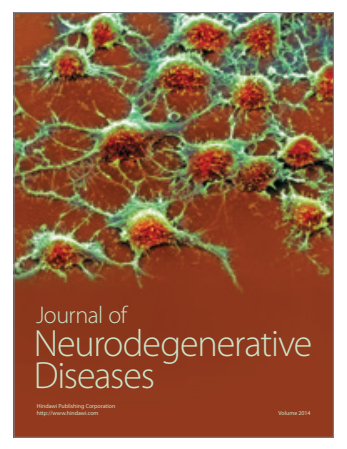

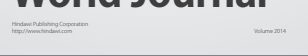

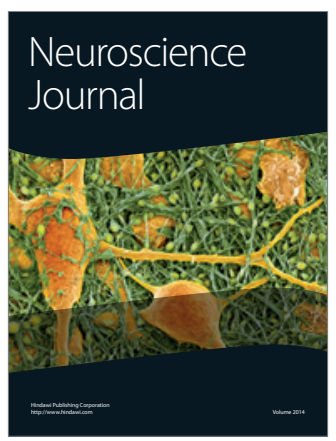

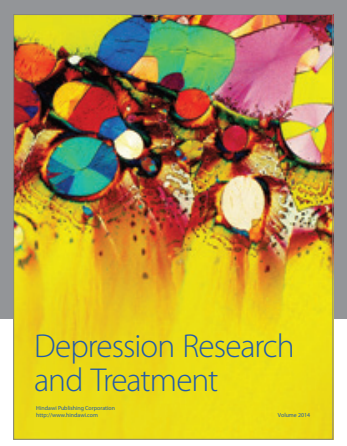
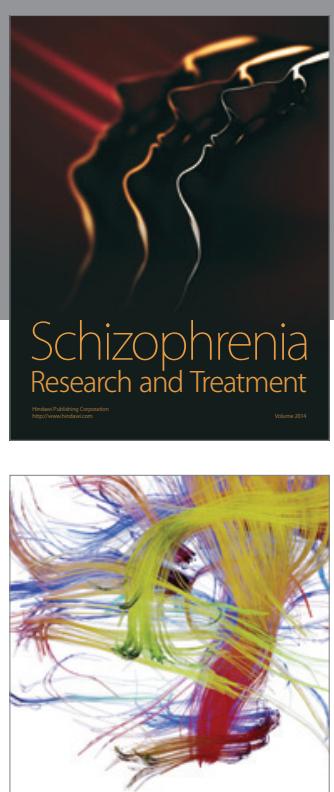

Brain Science

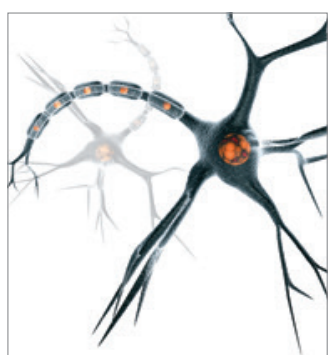

Neural Plasticity
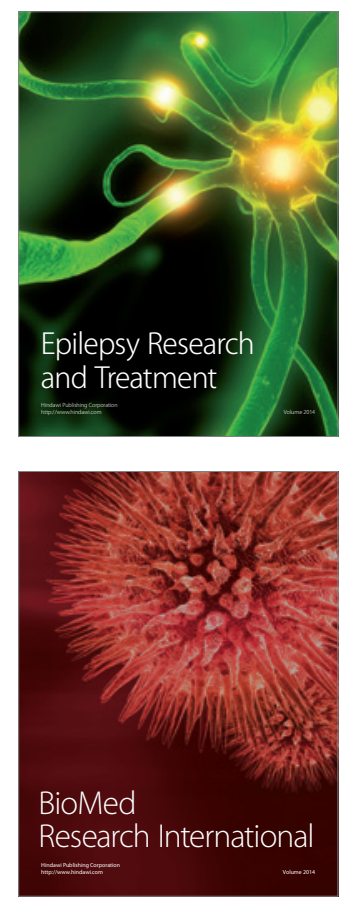

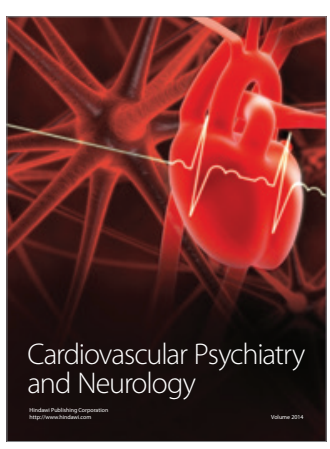

Parkinson's

Disease
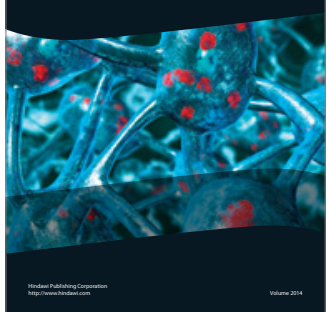